\title{
Ophthalmic Microsurgery Lab for Medical Students: Enhancing Learner Intrinsic Motivation and Comfort with Microsurgery
}

\author{
Joshua Cole, MSPH ${ }^{1}$ Tiffany A. Chen, MD² Tessnim Ahmad, MD² Neeti Parikh, MD² \\ ${ }^{1}$ University of California, San Francisco School of Medicine, San \\ Francisco, California \\ 2 Department of Ophthalmology, University of California, San \\ Francisco, California \\ Address for correspondence Neeti Parikh, MD, Department of \\ Ophthalmology, Wayne and Gladys Valley Center for Vision, \\ University of California, Box 4081, 490 Illinois Street, Floor 5, San \\ Francisco, CA 94143 (e-mail: Neeti.parikh@ucsf.edu).
}

J Acad Ophthalmol 2021;13:e234-e241.

\begin{abstract}
Keywords

- undergraduate medical education

- ophthalmology

- microsurgery

- motivation

- surgical simulation
\end{abstract}

Objective This study aimed to evaluate the impact of an ophthalmic microsurgery laboratory on medical students' intrinsic motivation, explicit interest in ophthalmology, and comfort with microsurgical skills.

Design In this noncontrolled trial, medical students attended a Zoom-based lecture on corneal suturing, watched an instructional video on operating microscopes, and attended a wet laboratory on corneal suturing. Participants completed pre- and posttest surveys assessing comfort with microsurgical skills and explicit interest in ophthalmology. Additionally, the posttest survey included items from the Intrinsic Motivation Inventory (IMI). Setting This study was conducted at a single academic medical center.

Participants A total of 20 students enrolled in the MD program at the University of California, San Francisco School of Medicine.

Results Pre- and posttest response rates were 100\% $(n=20)$ and 90\% $(n=18)$, respectively. Comfort with microsurgical skills increased significantly between preand posttest surveys with large effect sizes (95\% confidence interval [CI]; $p$-value): loading a needle, 1.67 (1.04-2.29; $p<0.001)$; passing a suture, $1.72(1.04-2.40$; $p<0.001)$; knot tying, $1.05(0.34-1.76$; $p=0.004)$; using a microscope, $0.83(0.04-$ 1.63; $p=0.040)$; and suturing under a microscope, $1.44(0.88-2.00 ; p<0.001)$. Comparing pre- and posttest surveys, students reporting moderate to extreme interest in ophthalmology increased from 44 to $61 \%$. Intrinsic motivation was high, indicated by the mean IMI Interest score reaching $93 \%$ of the maximum score. Multiple linear regression analyses predicted that IMI Interest scores increased with higher scores of familiarity $(p=0.002)$, explicit interest in ophthalmology $(p=0.042)$, and comfort with microscopes $(p=0.005)$, knot tying $(p=0.026)$, and performing surgical maneuvers under a microscope $(p=0.032)$.

Conclusion Ophthalmic microsurgery laboratories may increase medical students' explicit interest in ophthalmology, comfort with microsurgical skills, and intrinsic motivation. Future studies are needed to evaluate the impact of microsurgical electives on students' objective skills and specialty selection. received

April 13, 2021

accepted after revision

August 19, 2021
DOI https://doi.org/ $10.1055 / \mathrm{s}-0041-1740067$. ISSN 2475-4757.

\footnotetext{
(c) 2021. The Author(s).

This is an open access article published by Thieme under the terms of the Creative Commons Attribution-NonDerivative-NonCommercial-License, permitting copying and reproduction so long as the original work is given appropriate credit. Contents may not be used for commercial purposes, or adapted, remixed, transformed or built upon. (https://creativecommons.org/ licenses/by-nc-nd/4.0/)

Thieme Medical Publishers, Inc., 333 Seventh Avenue, 18th Floor, New York, NY 10001, USA
} 
The national supply of surgeons is projected to fall short of demand in 2025 with ophthalmology facing the greatest national-level physician shortage. ${ }^{1}$ Furthermore, medical students have traditionally displayed low interest in ophthalmology with only 2.5 to $3.1 \%$ of medical school graduates preferring ophthalmology from 2005 to 2015 . $^{2}$ A study on medical students' perception of ophthalmology showed that insufficient exposure was a predominant reason for not pursuing ophthalmology. ${ }^{3}$

Curricular time dedicated to ophthalmology in medical school has been declining; however, this decline has slowed and perhaps plateaued since $2014 .^{4,5}$ A survey by the Association of University Professors of Ophthalmology (AUPO) Medical Student Educators' Council found that ophthalmology teaching is largely incorporated into preclinical coursework, most commonly through lectures, followed by skills training and problem-based learning. ${ }^{4}$ Though all AUPO affiliated programs offered an ophthalmology elective, only a small percentage had a required elective. ${ }^{4}$ Clinical electives may offer minimal to no hands-on experience with ophthalmic surgery. The current number of ophthalmology hours and teaching methods during medical school may be insufficient to stimulate interest in ophthalmology.

Exposing medical students to ophthalmology during their undergraduate medical education is a crucial step to increasing student interest in ophthalmology and potentially addressing the nation's pipeline of future surgeons. Increased exposure to operative procedures, surgical staff, and surgical simulation laboratories can increase students' procedural skills and desire for surgical careers. ${ }^{6-11}$ Integration of a wet laboratory into elective ophthalmology blocks or other parts of the medical school curriculum can result in positive evaluations by medical students, including increased interest in ophthalmology. ${ }^{12,13}$ While previous studies have investigated the effect of surgical exposure and simulation laboratories on career interest in surgical fields, including ophthalmology, to our knowledge, none have focused on assessing the effect of ophthalmic microsurgical simulation laboratories on intrinsic motivation grounded in the Self-Determination Theory (SDT).

The SDT is a theory of human motivation postulating that three basic psychological needs-competence, autonomy, and relatedness-have to be satisfied to grow or achieve intrinsic motivation. ${ }^{14}$

The purpose of this study is to evaluate the impact of an ophthalmic microsurgery laboratory on student intrinsic motivation and interest in ophthalmology, as well as comfort with microsurgery. We hypothesize that single-event exposure to laboratory-based ophthalmic microsurgery would increase medical students' intrinsic motivation, explicit career interest in ophthalmology, and comfort with performing basic ophthalmic microsurgical tasks.

\section{Methods}

This study was conducted in August 2020 at the University of California, San Francisco (UCSF) School of Medicine and approved by the UCSF Institutional Review Board. Firstthrough third-year medical students were recruited on a first-come, first-serve basis using e-mail and Facebook posts on UCSF School of Medicine class pages. Fourth-year students were excluded as they had already chosen their subspecialty of interest.

\section{Intervention Design}

Participants attended a Zoom-based lecture facilitated by ophthalmology faculty as an introduction to microsurgery. The 25-minute lecture covered basic eye anatomy, ophthalmic microsurgical instruments, and corneal suturing. Prior to participating in the wet laboratory on corneal suturing, participants also watched a 5-minute instructional video on operating microscopes during which an ophthalmology faculty member and resident explained the basic microscope components that how to set the pupillary distance, focus and magnification, and appropriate use of the foot pedals.

Four microsurgery wet laboratory sessions were held. Each wet laboratory session accommodated only five students at a time to observe the novel coronavirus disease (COVID-19) precautions on social distancing. All students and instructors were required to pass a daily health screen within 4 hours of entering the wet laboratory and to wear personal protective equipment consisting of facemasks as per UCSF institutional policy. Ophthalmology residents and attending physicians were present to instruct participants during the workshop in a 5:3 student-to-educator ratio. During the 2-hour workshop, participants completed four progressively complex tasks in the following order: (1) macrosurgical suturing on a surgical sponge using a 5-0 prolene suture; (2) microscope setup, including setting the pupillary distance, practicing with the foot pedal, and adjusting focus and magnification; (3) three-dimensional (3D) task under the microscope (threading a standard sewing needle); and (4) microsurgical suturing under the microscope using 9-0 nylon sutures on a synthetic surgical simulation eye, PS016 (Phillips Studio, Bristol, United Kingdom). The fourth task involved a linear corneal laceration in the simulation eye on which students practiced corneal suturing with interrupted sutures (-Fig. 1A-D). The corneal suturing task consisted of four subtasks: loading a needle, passing a suture, tying a knot, and overall suturing under a microscope. Throughout the laboratory, supervising surgeons provided feedback and guidance to support students in completing these tasks.

\section{Data Collection Tools}

Participants completed pre- and posttest surveys to collect data on baseline demographics, prior surgery-related activities, factors influencing specialty preference, comfort with surgical skills, and self-reported interest and familiarity with ophthalmology. Rating of factors influencing specialty preference, comfort with surgical skills, and self-reported interest and familiarity with ophthalmology used a 5-point Likert's scale where $1=$ not at all important/interested, $2=$ slightly important/interested, 3 = moderately important/interested, $4=$ very important/interested, and $5=$ extremely important/interested. 

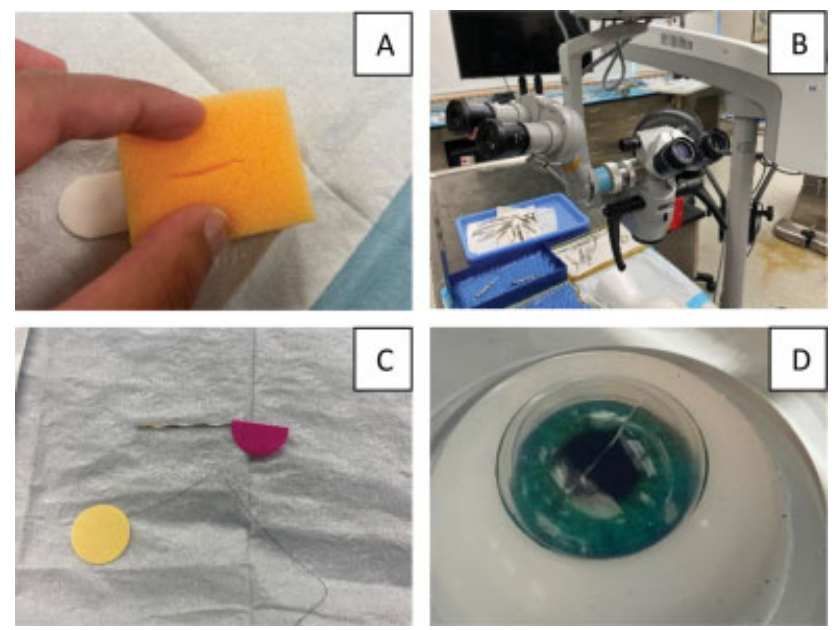

Fig. 1 Images of the wet laboratory's four progressively complex tasks. (A) Macrosurgical suturing on a surgical sponge using a 5-0 prolene suture, (B) microscope setup, (C) three-dimensional task under the microscope (threading a standard sewing needle), and (D) microsurgical suturing under the microscope using 9-0 nylon sutures on a synthetic surgical simulation eye with a corneal laceration (Phillips Studio, Bristol, United Kingdom).

We adapted the validated Intrinsic Motivation Inventory (IMI) for inclusion into the posttest survey. ${ }^{15,16}$ The survey consisted of five subscales (interest, perceived competence, pressure, effort, and value) assessed through 20 question items. Participants answered each item using a 7-point Likert's scale where $1=$ strongly disagree, $2=$ disagree; $3=$ somewhat disagree, $4=$ neither agree nor disagree, $5=$ somewhat agree, $6=$ agree, and $7=$ strongly agree.

In accordance with The American College of Surgeons, we defined surgery-related activities as those in one of the following 14 surgical specialties: (1) cardiothoracic surgery, (2) colon and rectal surgery, (3) general surgery, (4) gynecology and obstetrics, (5) gynecologic oncology, (6) neurological surgery, (7) ophthalmic surgery, (8) oral and maxillofacial surgery, (9) orthopaedic surgery, (10) otorhinolaryngology, (11) pediatric surgery, (12) plastic and maxillofacial surgery, (13) urology, and (14) vascular surgery.

\section{Outcomes}

The primary outcomes were the posttest IMI Composite and Interest subscale scores and predictive regression analyses of the IMI Interest subscale score as the outcome variable. Secondary outcomes included the differences between preand post-test Likert's scores for specialty preference factors, self-reported familiarity and interest in ophthalmology, and comfort with basic microsurgical tasks (loading a needle, passing a suture, knot tying, and suturing under a microscope).

\section{Statistical Analyses}

We performed data analysis using Stata Statistical Software: Release 14 (College Station, TX: StataCorp LP). We calculated the mean Likert's score for primary and secondary outcomes. Pre- and posttest effect sizes were assessed for significance with the paired Student's $t$-test $(p<0.05$ was considered statistically significant) and nonparametric Mann-Whitney $U$-tests or Fischer's exact tests (for low incidences).

Predictive statistical analysis involved several simple linear regression analyses of the IMI Interest subscale score or the Composite IMI score as the outcome variable with all pre- and posttest measures as predictors. Furthermore, stepwise estimation was performed to select a multiple linear regression model using forward and backward stepwise selection of statistically significant predictor variables. This iterative process starts with a model of the IMI Interest subscale score as the outcome variable and all predictor variables check the significance of each predictor variable and add or remove one predictor variable with the least significance each time, until all the remaining variables are statistically significant $(p<0.0750)$.

\section{Results}

Twenty medical students at the UCSF were selected on a firstcome, first-serve basis in August 2020. Eighteen participants completed the pre- and posttest surveys (response rate, 90\%); two participants were excluded because of incomplete posttest surveys. The study population consisted of 1 firstyear student, 10 second-year students, 4 third-year students, and 3 students in the MD-PhD program.

\section{Prior Exposure/Experience in Ophthalmology}

-Fig. 2 shows participants' prior nonophthalmology surgery-related activities (i.e., other surgical subspecialties) and ophthalmology-related activities. Of the participants, 15 (83\%) reported having participated in at least one nonophthalmology surgery-related activity with clinical shadowing as the most frequently reported experience $(n=12,67 \%$ of students). Eleven participants (61\%) reported having participated in at least one ophthalmology-related activity, with didactics and clinical shadowing being the most frequently reported activities ( $n=9,50 \%$ of students for both).

\section{Specialty Preference}

At baseline, 14 participants (78\%) reported a surgical specialty as their highest ranked career preference with the following specialties cited most frequently (count, percentage of the 14 responses): ophthalmology ( $n=6,43 \%)$; neurosurgery $(n=3,21 \%)$; and general surgery $(n=2,14 \%)$.

Participants also reported the influence of procedural skills, intellectual challenge, and patient relationships on their specialty preference. On both pre- and posttest surveys, $78 \%$ of participants reported that procedural skills were "very to extremely important" in influencing specialty preference, while $17 \%$ of participants reported that procedural skills were "not at all important." Mean Likert's scores for the influence of procedural skill were identical between pre- and posttest surveys (mean $=4 ; 95 \%$ confidence interval $[\mathrm{CI}]$ : $3.46-4.54 ; p=1.000$. Mann-Whitney test showed no statistically significant difference between pre- and posttest responses in the underlying distributions of Likert's scores for procedural skills as an influence on specialty preference $(p=1.000)$. 


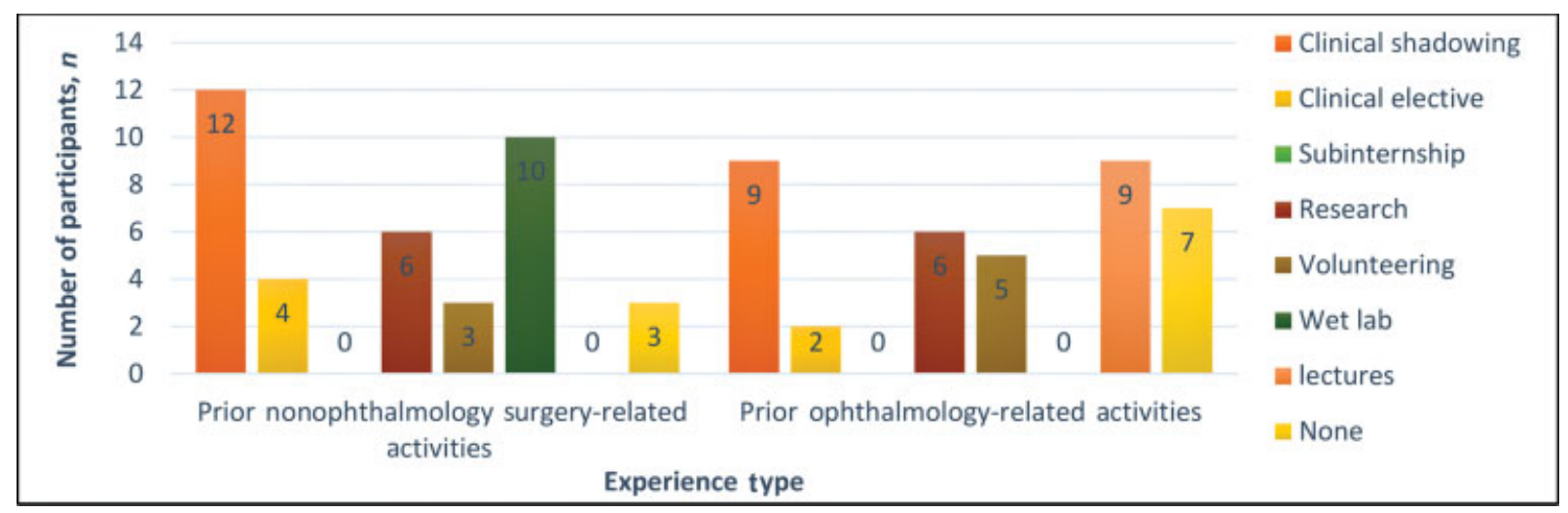

Fig. 2 Distribution of prior surgery-related activities in ophthalmology and other surgical subspecialties. We defined surgery-related activities as activities in one of the following 13 surgical specialties, excluding ophthalmology: cardiothoracic surgery, colon and rectal surgery, general surgery, gynecology and obstetrics, gynecologic oncology, neurological surgery, oral and maxillofacial surgery, orthopaedic surgery, otorhinolaryngology, pediatric surgery, plastic and maxillofacial surgery, urology, and vascular surgery.

All participants reported that intellectual challenge was "moderately important" to "extremely important" in specialty preference. There was no statistically significant difference in mean Likert's scores for intellectual challenge between pre- and posttests $(p=1.000)$ or the distribution of Likert's scores $(p=0.958)$. Seventy-eight percent of participants reported that patient relationships were "very important" or "extremely important" in specialty choice on both pre- and posttest surveys. There was no statistically significant difference between pre- and posttest mean Likert's scores for patient relationship $(p=0.680)$ or the distribution of Likert's scores $(p=0.888)$.

\section{Familiarity and Interest in Ophthalmology}

Between pre- and posttest surveys, the percentage of participants reporting to be "not at all familiar" to "slightly familiar" with ophthalmology as a career declined from 61 to $12 \%$, while the percentage of "moderately familiar" to "extremely familiar" increased from 38 to 55\% (-Fig. 3A). However, there were no statistically significant differences in mean Likert's scores $(p=0.131)$ or the distribution of responses $(p=0.153)$. Similarly, students reporting to be "moderately interested" to "extremely interested" in ophthalmology increased from 44 to $61 \%$, without statistical significance ( $p=0.689 ;$ - Fig. 3B).

\section{Comfort with Ophthalmic Microsurgery Surgical Skills} Comfort with ophthalmic surgical skills significantly increased between pre- and posttest surveys for all five skills based on mean Likert's scores with the greatest increase observed in comfort with passing a suture, 1.72 (1.04-2.49; $p<0.001$; - Table 1).

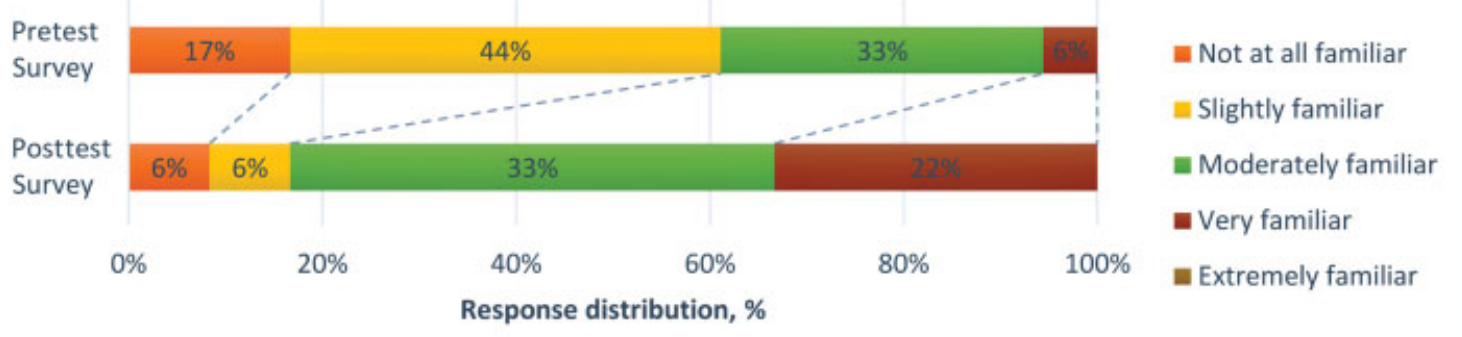

A

Response distribution, \%

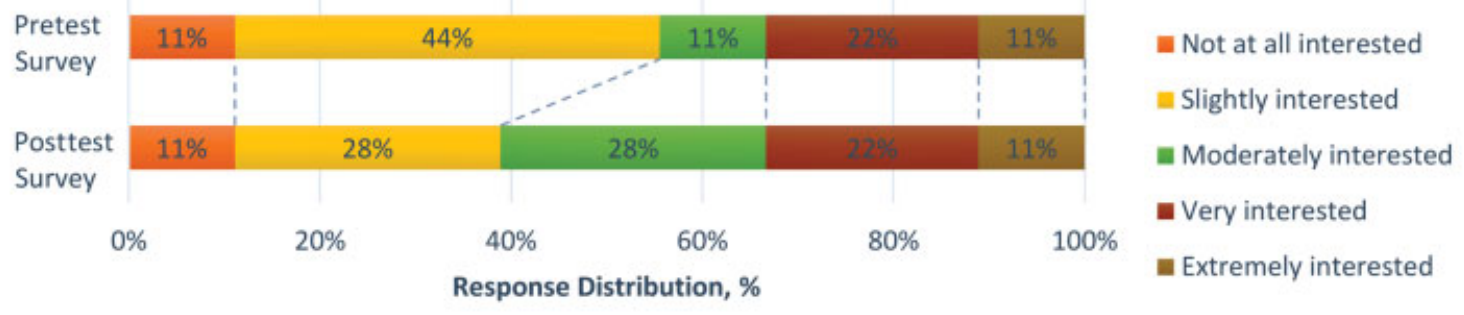

$\mathbf{B}$

Fig. 3 (A) How familiar are you with ophthalmology as a career? (B) How interested are you in ophthalmology as a career? 
Table 1 Pre- and posttest mean Likert's scores for comfort with microsurgical skills

\begin{tabular}{|c|c|c|c|c|}
\hline Microsurgical skill & $\begin{array}{l}\text { Pretest mean } \\
\text { Likert's score (SD) }\end{array}$ & $\begin{array}{l}\text { Posttest mean } \\
\text { Likert's score (SD) }\end{array}$ & $\begin{array}{l}\text { Effect size } \\
(95 \% \mathrm{Cl})\end{array}$ & p-Value \\
\hline Loading a needle & $1.83(0.85)$ & $3.50(0.98)$ & $1.66(1.04-2.20)$ & $<0.001$ \\
\hline Passing a suture & $1.55(0.85)$ & $3.27(1.12)$ & $1.72(1.04-2.40)$ & $<0.001$ \\
\hline Knot tying & $1.94(0.80)$ & $3.00(1.23)$ & $1.05(0.34-1.76)$ & 0.005 \\
\hline Using a microscope & $2.61(1.28)$ & $3.44(1.04)$ & $0.83(0.04-1.62)$ & 0.040 \\
\hline Suturing under a microscope & $1.50(0.85)$ & $2.94(0.80)$ & $1.44(0.88-2.00)$ & $<0.001$ \\
\hline
\end{tabular}

Abbreviations: $\mathrm{Cl}$, confidence interval; SD, standard deviation.

Table 2 Posttest intrinsic motivation scores

\begin{tabular}{|c|c|c|c|c|c|}
\hline $\begin{array}{l}\text { Intrinsic motivation } \\
\text { inventory subscales }\end{array}$ & Mean (SD) & Minimum & Maximum & $\begin{array}{l}\text { Highest } \\
\text { possible score }\end{array}$ & $\begin{array}{l}\text { Percentage of } \\
\text { highest possible } \\
\text { score (\%) }\end{array}$ \\
\hline Interest score & $19.44(1.88)$ & 16 & 21 & 21 & 92.57 \\
\hline Effort score & $11.66(1.94)$ & 7 & 14 & 14 & 83.28 \\
\hline Pressure score & $10.61(3.82)$ & 3 & 18 & 21 & 50.52 \\
\hline Value score & $18.22(2.75)$ & 13 & 21 & 21 & 86.76 \\
\hline Competence score & $18.50(5.18)$ & 8 & 27 & 28 & 66.07 \\
\hline Composite score & $78.44(8.15)$ & 66 & 89 & 105 & 74.70 \\
\hline
\end{tabular}

Abbreviation: SD, standard deviation.

\section{Intrinsic Motivation Inventory Scores}

We used the IMI scores to determine whether the microsurgical training influenced students' intrinsic motivation. The Interest subscale, which is considered the self-reported measure of intrinsic motivation, demonstrated the largest mean (standard deviation) score of 19.44 (1.88), reaching 93\% of the maximum possible score (-Table 2 ).

\section{Predictive Regression Analyses}

To explore the relationship between IMI Composite scores with predictor variables, we performed simple and multiple linear regressions which demonstrated that composite IMI scores increased with improved posttest Likert's scores of comfort with loading a needle $(\mathrm{B}=2.86$ [CI: 0.39-5.32]; $p=0.026)$ and explicit interest in ophthalmology $(2.78$ [ -0.46 to 6.03 ]; $p=0.088$ ). Forward and backward stepwise regressions generated similar findings.

Given that the IMI Interest subscale is the most direct measure of intrinsic motivation, we also explored its relationship with predictor variables. Our analyses revealed that the Interest IMI subscale increased significantly with five independent factors ( - Table $3 ; p=0.005$ ). Approximately $82 \%$ of the variability in Interest subscale scores was accounted for by the variables in the model.

\section{Discussion}

Previous studies have investigated the effect of surgical exposure and simulation laboratories on career interest in surgical fields, including ophthalmology, though, to our
Table 3 Results of stepwise linear regression analyses with IMI interest subscale score as the outcome variable

\begin{tabular}{|l|l|l|}
\hline Predictor variable & $\mathbf{B}(95 \% \mathrm{Cl})^{\mathbf{b}}$ & $p$-Value \\
\hline $\begin{array}{l}\text { Comfort with using } \\
\text { microscope, posttest }\end{array}$ & $1.17(0.40-1.9)$ & 0.005 \\
\hline Knot tying skills, pretest & $1.76(0.26-3.2)$ & 0.026 \\
\hline $\begin{array}{l}\text { Familiarity with } \\
\text { ophthalmology, posttest }\end{array}$ & $2.36(1.10-3.6)$ & 0.002 \\
\hline $\begin{array}{l}\text { Comfort with performing } \\
\text { surgical maneuvers under a } \\
\text { microscope, pretest }\end{array}$ & $1.25(0.13-2.4)$ & 0.032 \\
\hline $\begin{array}{l}\text { Interest in } \\
\text { ophthalmology, pretest }\end{array}$ & $0.97(0.04-1.90)$ & 0.042 \\
\hline
\end{tabular}

Abbreviations: $\mathrm{Cl}$, confidence interval; IMI, Intrinsic Motivation Inventory.

${ }^{a} p$-Values show the significance of the predictive value of each independent variable on the different outcome variables.

${ }^{b} \mathrm{~B}$ values are unstandardized regression coefficients that indicate the amount of change one could expect in IMI interest score given a oneunit change in the value of that variable all other variables in the model are held constant.

knowledge, none have assessed the effect of ophthalmic microsurgical simulation laboratories on intrinsic motivation. In our study, we administered the IMI tool, which is validated for assessing participants' subjective experience of an intervention, and which has been used in studies on intrinsic motivation across disciplines, including clinical education. $^{17,18}$ 
Our study demonstrated that a single ophthalmic microsurgery laboratory may increase students' intrinsic motivation, comfort with microsurgical tasks, and explicit familiarity with and interest in ophthalmology. Using the IMI scores as dependent measures for the purpose of prediction, we observe that students with high scores for comfort with microscopes, familiarity with ophthalmology, comfort with loading a needle, and explicit interest in ophthalmology are more likely to report higher intrinsic motivation. Out of the five measured subscales, the Interest subscale had the largest absolute value and percentage of maximum value, while the pressure subscale displayed the lowest absolute value and percentage. The Interest subscale assesses interest and inherent pleasure when performing a specific activity and is the most direct measure of intrinsic motivation. ${ }^{19}$ The value subscale refers to internalization in which the person identifies with the value of an experience and develops selfregulatory activities. The Effort subscale assesses the individual's investment of their capacities into the activity. ${ }^{19,20}$ Finally, studies have shown pressure to be a negative predictor of intrinsic motivation. ${ }^{19,21}$ Thus, a significantly high Interest subscale would result if the positive predictors are high and the negative predictors are low which is observed in our study.

Furthermore, perceived competence is theorized to be a positive predictor of intrinsic motivation. Our participants' perceived competence scores averaged to $66 \%$ of the maximum scores, which correlates with their increasing, yet moderate level of comfort with several subtasks of the intervention. Studies have shown that increased perceived competence and interest within an autonomous supportive learning climate predicted specialty choice. ${ }^{22}$ Our study participants reported high absolute values and percentage of maximum value for Interest and Value subscales, suggesting that their likelihood of pursuing ophthalmology-related activities may have increased; however, future monitoring is needed to validate this prediction.

Our predictive statistical analyses show that both multiple and linear regression models were significant, indicating that the overall models were significant. The variability in Interest subscale scores was mostly accounted for by the predictor variables. This suggests that increasing posttest comfort with microscopes and familiarity with ophthalmology and increasing pretest comfort with surgical maneuvers under a microscope, knot tying skills, and interest in ophthalmology could augment intrinsic motivation. Comfort with microscopes may be an important factor of intrinsic motivation for ophthalmology. The ability to integrate detailed visual information with fine manual dexterity using stereovision under a microscope is critical to ophthalmic microsurgery. Thus, it is plausible that increased comfort with the microscope positively predicts interest in ophthalmology. Studies show that stereoscopic depth perception is advantageous when initially learning to perform surgical skills under an operating microscope and that poor hand-eye coordination was the most common problem for ophthalmology residents failing to develop sufficient quality surgical skills. $^{23,24}$ As such, early exposure to the microsurgery laboratory may allow students to determine if they are a good fit for subspecialties like ophthalmology.

The implications of this 120-minute laboratory are considerable, suggesting that single-event activities can bolster student interest, comfort, and intrinsic motivation. The application of SDT and intrinsic motivation to medical education has generated evidence across numerous domains to guide curriculum design and elucidate learning processes in clinical education settings. ${ }^{18,25}$ Intrinsic motivation is an important aspect to consider when designing medical student experiences, particularly for ophthalmology exposure, because it is associated with increased deep learning, perseverance, well-being, specialty interest, and likelihood of specialty selection. ${ }^{14,22,26-31}$ Studies have shown that single-event surgery laboratories for medical students can increase interest in surgery alongside competence in surgical-suturing techniques and advanced surgical procedures. $^{6,8}$ Several single-event ophthalmology laboratories may be logistically easier to implement than clinical electives which afford opportunities to counteract the national trend of ophthalmology education shifting to preclinical years ${ }^{5}$ by offering longitudinal integrated clinical years. Studies on microsurgical training for medical students have shown that several regularly interspersed training sessions can improve skill acquisition. ${ }^{32,33}$

\section{Strengths and Limitations}

Strengths of our study included a high response rate, anonymous surveys, robust statistical analysis, and a well-crafted wet-laboratory course. There are several limitations to this study. Our sample size was limited by COVID-19 public health precautions, number of operating microscopes, short intervention duration, and desired learner-to-educator ratio. A selection bias may have arisen as students who volunteered to participate may have baseline characteristics that distinguish them from nonparticipants such as greater interest in ophthalmology or other surgical subspecialties, motivation by relationships with the research team, prior ophthalmology experience, or in need of suturing skills practice to prepare for surgery rotations. Selection bias relating to the recruitment process may have also occurred as we recruited participants via e-mail and Facebook posts which is biased against individuals with limited access to Facebook, e-mail, or the internet. Random selection of participants and a multimodal recruitment process could have mitigated the distortion of our study's effect size and confidence intervals. This would also help increase our sample size and medical student participation.

Regarding the surveys, the pretest survey did not include detailed questions on the exact frequency, length, type, or extent of involvement in surgical experiences which may have impacted participants' comfort. Additionally, the study's primary outcomes exclusively involved subjective measures. Inclusion of objective measures in future studies to determine the effects of ophthalmic microsurgical training on skill building is warranted. Furthermore, nonuse of procedural skills risks decay; hence, it is important to consider more prolonged and frequent microsurgical simulation 
experiences. Heterogeneity in teaching styles among resident and attending ophthalmologists could have impacted the social context in which each participant completed the training, thereby affecting each student's subjective selfassessment. Lastly, this study did not afford long-term follow-up to determine the effect on students' pursuit of ophthalmology experiences and residency selection. Further studies with larger sample sizes and multisession interventions should be conducted using randomization and the development of objective measures to assess the effectiveness of ophthalmic wet laboratories on intrinsic motivation, microsurgical skills, and pursuit of ophthalmology, including monitoring of residency selection outcomes.

\section{Conclusion}

Ophthalmic microsurgery laboratories for medical students can result in high intrinsic motivation, increased explicit interest in ophthalmology, and comfort with basic ophthalmic surgical tasks.

Incorporating ophthalmic microsurgery wet laboratories, with an emphasis on basic microscope competence into preclinical ophthalmologic teaching, longitudinal electives, or extracurricular opportunities could increase engagement, understanding, and interest in ophthalmology as a career.

\section{Competencies}

Patient Care and Procedural Skills, Medical Knowledge.

\section{Funding}

This work was supported in part by a Research to Prevent Blindness unrestricted grant to the Department of Ophthalmology, University of California San Francisco. The Funding source had no involvement in the study design, collection, analysis, data interpretation, manuscript writing, or decision to publish.

\section{Conflict of Interest}

None declared.

\section{References}

1 U.S. Department of Health and Human Services, Health Resources and Services Administration, National Center for Health Workforce Analysis. National and Regional Projections of Supply and Demand for Surgical Specialty Practitioners: 2013-2025. Accessed September 2, 2021 at: https://bhw.hrsa.gov/sites/ default/files/bureau-health-workforce/data-research/surgicalspecialty-report.pdf

2 Xierali IM, Nivet MA, Wilson MR. Current and future status of diversity in ophthalmologist workforce. JAMA Ophthalmol 2016; 134(09):1016-1023

3 Linz MO, Jun AS, Clever SL, Lawson SM, Sanyal A, Scott AW. Evaluation of medical students' perception of an ophthalmology career. Ophthalmology 2018;125(03):461-462

4 Shah M, Knoch D, Waxman E. The state of ophthalmology medical student education in the United States and Canada, 2012 through 2013. Ophthalmology 2014;121(06):1160-1163

5 Moxon NR, Goyal A, Giaconi JA, et al. The state of ophthalmology medical student education in the United States: an update. Ophthalmology 2020;127(11):1451-1453
6 Seo HS, Eom YH, Kim MK, Kim Y-M, Song BJ, Song KY. A one-day surgical-skill training course for medical students' improved surgical skills and increased interest in surgery as a career. BMC Med Educ 2017;17(01):265

7 Lee JT, Son JH, Chandra V, Lilo E, Dalman RL. Long-term impact of a preclinical endovascular skills course on medical student career choices. J Vasc Surg 2011;54(04):1193-1200

8 Khatib M, Soukup B, Boughton O, Amin K, Davis CR, Evans DM. Plastic surgery undergraduate training: how a single local event can inspire and educate medical students. Ann Plast Surg 2015;75 (02):208-212

9 Lee JT, Qiu M, Teshome M, Raghavan SS, Tedesco MM, Dalman RL. The utility of endovascular simulation to improve technical performance and stimulate continued interest of preclinical medical students in vascular surgery. J Surg Educ 2009;66(06): 367-373

10 Drosdeck J, Carraro E, Arnold M, et al. Porcine wet lab improves surgical skills in third year medical students. J Surg Res 2013;184 (01):19-25

11 Sideris M, Papalois A, Theodoraki K, et al. Promoting undergraduate surgical education: current evidence and students' views on ESMSC international wet lab course. J Invest Surg 2017;30(02): 71-77

12 Müller A, Pfeiffer N, Schmidt F, Prokosch V. A microsurgical wet lab for medical students increases interest in ophthalmology [in German]. Ophthalmologe 2020;117(11):1087-1091

13 Enders C, Schneider A, Keis O, et al. Innovative teaching methods: wet lab-based ophthalmosurgical education for medical students [in German]. Klin Monatsbl Augenheilkd 2019;236(07):911-918

14 Ryan RM, Deci EL. Self-determination theory and the facilitation of intrinsic motivation, social development, and well-being. Accessed September 2, 2021 at: https://selfdeterminationtheory.org/SDT/documents/2000_RyanDeci_SDT.pdf

15 Intrinsic Motivation Inventory (IMI) - selfdeterminationtheory.org. Accessed March 31, 2021 at: https://selfdeterminationtheory.org/intrinsic-motivation-inventory/

16 Ryan RM. Control and information in the intrapersonal sphere: An extension of cognitive evaluation theory. J Pers Soc Psychol 1982; 43(03):450-461

17 Ostrow K, Heffernan N. Testing the validity and reliability of intrinsic motivation inventory subscales within ASSISTments. In: Rosé CP, Martínez-Maldonado R, Hoppe HU, et al, eds. Artificial Intelligence in Education. London, United Kingdom: 19th International Conference, AIED 2018; 2018:381-394

18 Orsini C, Evans P, Jerez O. How to encourage intrinsic motivation in the clinical teaching environment?: a systematic review from the self-determination theory J Educ Eval Health Prof 2015;12:8

19 Monteiro V, Mata L, Peixoto F, Monteiro V, Mata L, Peixoto F. Intrinsic motivation inventory: psychometric properties in the context of first language and mathematics learning. Psicol Reflex Crit 2015;28(03):434-443

20 Deci EL, Eghrari H, Patrick BC, Leone DR. Facilitating internalization: the self-determination theory perspective. J Pers 1994;62 (01):119-142

21 Plant RW, Ryan RM. Intrinsic motivation and the effects of selfconsciousness, self-awareness, and ego-involvement: an investigation of internally controlling styles. J Pers 1985;53(03): 435-449

22 Williams GC, Saizow R, Ross L, Deci EL. Motivation underlying career choice for internal medicine and surgery. Soc Sci Med 1997;45(11):1705-1713

23 Nibourg LM, Wanders W, Cornelissen FW, Koopmans SA. Influence of stereoscopic vision on task performance with an operating microscope. J Cataract Refract Surg 2015;41(09):1919-1925

24 Binenbaum G, Volpe NJ. Ophthalmology resident surgical competency: a national survey. Ophthalmology 2006;113(07):1237-1244

25 Ten Cate TJ, Kusurkar RA, Williams GC. How self-determination theory can assist our understanding of the teaching and learning 
processes in medical education. AMEE guide no. 59. Med Teach 2011;33(12):961-973

26 Williams GC, Wiener MW, Markakis KM, Reeve J, Deci EL. Medical students' motivation for internal medicine. J Gen Intern Med 1994;9(06):327-333

27 Deci EL, Ryan RM. Facilitating optimal motivation and psychological well-being across life's domains. Can Psychol Can 2008;49(01):14

28 Kusurkar RA, Croiset G, Galindo-Garré F, Ten Cate O. Motivational profiles of medical students: association with study effort, academic performance and exhaustion. BMC Med Educ 2013;13:87

29 Kusurkar RA, Ten Cate TJ, van Asperen M, Croiset G. Motivation as an independent and a dependent variable in medical education: a review of the literature. Med Teach 2011;33(05):e242-e262
30 Covington MV. Goal theory, motivation, and school achievement: an integrative review. Annu Rev Psychol 2000;51:171-200

31 Walker CO, Greene BA, Mansell RA. Identification with academics, intrinsic/extrinsic motivation, and self-efficacy as predictors of cognitive engagement. Learn Individ Differ 2006;16(01):1-12

32 Scholz M, Mücke T, Hölzle F, et al. A program of microsurgical training for young medical students: are younger students better? Microsurgery 2006;26(06):450-455

33 Mücke T, Borgmann A, Ritschl LM, Kesting MR, Loeffelbein DJ, Wolff K-D. Microvascular training of medical students and surgeons - a comparative prospective study. J Craniomaxillofac Surg 2013;41(08):e187-e190 